\title{
ESTÁGIO CURRICULAR SUPERVISIONADO: IDENTIDADE E SABERES DOCENTES
}

\begin{tabular}{c} 
SUPERVISED INTERNSHIP: \\
IDENTITY AND KNOWLEDGE TEACHERS \\
\hline PRÁCTICA CURRICULAR SUPERVISADA: \\
IDENTIDAD Y SABERES DOCENTES \\
\hline
\end{tabular}

\begin{abstract}
RESUMO: O objetivo deste artigo é discutir os desafios encontrados na prática docente como formadores de professores de Geografia e História na disciplina de Estágio Curricular Supervisionado. Para tanto, tomamos o Estágio como locus privilegiado das discussões dos saberes docentes como construtores de um núcleo de saberes profissionais, importante à socialização profissional e à construção da identidade docente. Procuramos, entre os autores Pimenta e Lima (2010), Nóvoa (1992), Moita (1992), Gauthier (1998), Shön (2000) e Tardif (2012), contribuições teóricas para subsidiar nossas discussões sobre a formação de professor que integre três eixos: estágio curricular supervisionado, identidade e saberes docentes. A conclusão a que chegamos é de que o Estágio Supervisionado é um espaço privilegiado de discussão acerca dos saberes docentes, que são constitutivos da identidade e profissionalização docente.
\end{abstract}

PALAVRAS-CHAVE: Estágio supervisionado. Saberes docentes. Identidade docente.

ABSTRACT: The purpose of this article is to discuss the challenges in teaching practice as Geography teacher trainers and history in the discipline Supervised. Therefore, it takes the stage as a privileged locus of discussions of teaching knowledge as builders of a core of professional knowledge, important to the professional socialization and the construction of teacher identity. Seek, among the authors Pimenta and Lima (2010); Nóvoa (1992); Moita (1992); Gauthier (1998); Shön (2000) and Tardif (2012) theoretical contributions to support our discussions about teacher training that integrates three axes: supervised traineeship, identity and teaching knowledge. The conclusion we reached is that the Supervised Internship is a privileged space for discussion about the teaching knowledge, which are constitutive of identity and teacher professionalization.

KEYWORDS: Supervised internship. Teaching knowledges. Teacher identity.

RESUMÉN: El objetivo de este artículo es discutir los desafíos encontrados en la práctica docente como formadores de profesores de Geografía e Historia en la asignatura de Práctica Curricular Supervisado. Para eso, se toma la Práctica como locus privilegiado de las discusiones de los saberes docentes como constructores de un núcleo de saberes profesionales, importante a la socialización profesional y a la construcción de la identidad docente. Buscamos, entre los autores Pimenta y Lima (2010), Nóvoa (1992), Moita (1992), Gauthier (1998), Shön (2000) y Tardif (2012), contribuciones teóricas para subsidiar nuestras discusiones sobre la formación de profesor que integre tres ejes: Práctica curricular supervisada, identidad y saberes docentes. La conclusión a la que llegamos es que la Práctica Supervisada es un espacio privilegiado de discusión acerca de los saberes docentes, que son constitutivos de la identidad y profesionalización docente.

PALABRAS CLAVE: Práctica supervisada. Saberes docentes. Identidad docente.

Submetido em: 13/10/2016 - Aceito em: 06/09/2017 - Publicado em: 20/03/2018

\begin{tabular}{l|c|c|c|c|c|c|} 
(C) Rev. Educ. Perspec. & Viçosa, $M G$ & v.9 & n.1 & p.30-47 & jan./abr. 2017 & eISSN 2178-8359 \\
\hline
\end{tabular}




\section{INTRODUÇÃO}

Ao iniciarmos as atividades previstas para a disciplina Estágio Supervisionado nos Cursos de Licenciatura em Geografia e em História deparamo-nos com o desafio de subsidiar nossos licenciandos com as informações mínimas e necessárias à um processo de observação da prática docente de forma mais eficiente, eficaz e, por que não dizer, prazeroso. Para tanto, partimos do pressuposto de que o Estágio Supervisionado pode e deve assumir o caráter do "trabalho de campo".

É prática comum e corrente nos cursos de graduação em Geografia e História, no Brasil, a realização de trabalhos de campo, no qual, os alunos de posse de um embasamento teórico, partem para observação empírica dos fenômenos estudados. Considerando que o Estágio Supervisionado objetiva ressaltar a importância da aprendizagem da Geografia e da História e discutir as responsabilidades do professor no processo ensino-aprendizagem, inferimos que nosso espaço de estudo é um campo extremamente dinâmico que envolve o professor, o aluno, todos os profissionais da educação, o currículo e o cotidiano escolar onde se desenvolvem as ações educativas, numa relação de mútua interdependência.

Deparamos, pois, com três grandes desafios: a) trabalhar a diferença entre Estágio Curricular Supervisionado e Estágio Profissional; b) despertar nos alunos a compreensão de que a construção da identidade docente se inicia antes mesmo da formação acadêmica e continua no exercício da docência, permeada por diversos saberes; c) evidenciar para os estagiários a vinculação dessa pluralidade de saberes como construtores e reconstrutores de um núcleo de saberes profissionais, importante e necessário à socialização profissional e à construção da identidade docente.

\section{O ESTÁGIO CURRICULAR SUPERVISIONADO E O ESTÁGIO PROFISSIONAL}

Ao iniciarmos os trabalhos com a disciplina Estágio Curricular Supervisionado, deparamos, inicialmente, com a necessidade de diferenciar o Estágio Curricular do Estágio Profissional. Enquanto o Estágio Profissional objetiva inserir o formando no campo de trabalho, no intuito de experimentar e exercitar a profissão, o Estágio Curricular Supervisionado visa, além dessa inserção, que as discussões e reflexões decorrentes das observações e vivências realizadas no campo de Estágio integrem realmente o processo de formação do futuro professor. Isso significa conceber o campo de atuação no qual está inserido como objeto de análise, de investigação, ou seja, "campo de conhecimento" (PIMENTA; LIMA, 2010, p. 24).

\begin{tabular}{l|c|c|c|c|c|c} 
(C) Rev. Educ. Perspec. & Viçosa, $M G$ & v.9 & n.1 & p.30-47 & jan./abr. 2017 & eISSN 2178-8359 \\
\hline
\end{tabular}


Considerar o Estágio Curricular Supervisionado como campo de conhecimento implica superar a tradicional redução a ele atribuída de ser principalmente uma atividade prática instrumental. Concebê-lo como campo de conhecimento pode ser um bom passo para se alcançar a interação acadêmica tão desejável entre cursos de Licenciatura e a escola campo, haja vista que todos os sujeitos envolvidos são agentes formadores, uma vez que a profissão docente é uma construção processual, que se efetiva no dia a dia e que envolve/mobiliza diferentes saberes.

Portanto, ao observarmos a prática docente, no Campo de Estágio, tomando-o no/como campo de conhecimento, precisamos inicialmente considerar o processo de constituição da Identidade Docente. Como se forma um professor? O que é necessário saber para ser professor?

Com o objetivo de fornecer pistas que possam contribuir para que os estagiários construam respostas possíveis às questões acima, apresentamos, a seguir, algumas reflexões decorrentes de estudos desenvolvidos ao longo de nossa história acadêmica.

\section{IDENTIDADE DOCENTE: UMA CONSTRUÇÃO COTIDIANA}

Conforme Nóvoa (1992) na segunda metade do século XX ocorreu uma expansão dos sistemas educativos. Em decorrência, ocorreu também a introdução, por diversas vias, de modelos racionalistas de ensino, que, apesar de úteis, acabaram por contribuir, em grande escala, para o processo de desprofissionalização docente, ao desconsiderarem a "internalidade" do processo educativo.

Ao centrar-se nas aprendizagens acadêmicas, os modelos racionais de ensino reduzem a profissão docente a um conjunto de competências e de capacidades, intensificando o controle sobre os docentes, o que contribuiu para a crise de identidade dos professores.

A publicação do livro "O professor é uma pessoa", de Ada Abraham, em 1984, foi, segundo Nóvoa (1992), a mola propulsora a desencadear a invasão da literatura pedagógica por publicações de estudos sobre a vida, obra, carreiras, percursos, desenvolvimento pessoal de professores, cujo mérito indiscutível foi o de "recolocar os professores no centro dos debates educativos e das problemáticas da investigação" (NÓVOA, 1992, p. 15).

$\mathrm{Na}$ "forma" de ensinar, de conduzir o processo de ensino-aprendizagem, existe um conteúdo implícito, ou seja, a concepção de homem, de tempo, de espaço, de sociedade, de educação, de vida, que o professor foi construindo ao longo de sua existência e que acaba por explicitarse em seus atos, suas atitudes, em sua maneira de ser e de estar na profissão.

\begin{tabular}{l|c|c|c|c|c|c|} 
(C) Rev. Educ. Perspec. & Viçosa, $M G$ & v.9 & n.1 & p.30-47 & jan./abr. 2017 & eISSN 2178-8359 \\
\hline
\end{tabular}


Nesse sentido, considerando que o professor é uma pessoa e que, como tal, é um ser em constante construção, podemos deduzir que o processo identitário do professor é dinâmico e complexo, pois nos tornamos e/ou nos fazemos professores no nosso dia a dia, quer nos cursos de formação inicial, quer nos cursos de formação continuada, quer no exercício da função ou até mesmo em atividades que, aparentemente, podem não ter relação direta com a profissão. É no exercício da docência, seja em sala de aula, ou na preparação das ações pedagógicas, que nos fazemos professores, já que o professor constrói sua identidade na prática, no "habitus", ao mobilizar os diferentes saberes inerentes ao exercício de sua função.

Assim, concebendo a identidade como um processo, como uma construção cotidiana e sendo o homem um ser sócio-histórico que desempenha suas relações sociais de trabalho num tempo e espaço históricos, contraditório, múltiplo e real, podemos concluir que o homem constrói sua identidade ao produzir as condições necessárias para sua sobrevivência.

O homem, como ser social, ao buscar a produção das condições de sua sobrevivência, estabelece relações com o seu próximo e nessas relações constrói a vida humana. Nessa perspectiva, o homem precisa da sociedade para sobreviver e, como tal, procura, ao desempenhar sua atividade/profissão, fazer-se útil a essa sociedade, isto é, desenvolver uma função que satisfaça, além das suas próprias necessidades, desejos e anseios do grupo social no qual se insere.

É por sua atividade, isto é, pelo exercício da função, que o homem se relaciona com o meio social, estabelecendo um processo mútuo de troca das condições de sobrevivência. Nesse caso, a atividade humana influi no grupo social e é por ele influenciada, fazendo-se, portanto, necessário um processo de reflexão, de busca de consciência do homem sobre a atividade que exerce. Pela atividade desenvolvida, o homem passa a ser identificado e a identificar-se socialmente. 'Exerço a atividade docente, logo, sou professor'.

Ao considerar a questão da identidade, podemos incorrer no equívoco de relacioná-la única e exclusivamente à atividade desempenhada na sociedade. No entanto, é necessário considerar a identificação, o envolvimento, o comprometimento com aquilo que se faz, já que não basta estar na função, como também é necessário se fazer enquanto tal. Esse processo de se 'fazer', de se construir enquanto identidade requer, além do exercício da atividade, uma reflexão, uma busca de consciência daquilo que se faz, rompendo com a visão imposta pela teoria funcionalista, ou seja, de restringir a análise do processo de identidade do indivíduo às relações mais superficiais, mais aparentes dos jogos sociais.

A ausência do exercício reflexivo pode fazer com que alguns professores procurem imitar modelos/padrões do 'bom professor', por acreditarem que o bom desempenho da função que é descrita para o professor os tornará, por consequência, bons professores. Ora, é na prática,

\begin{tabular}{l|c|c|c|c|c|c} 
(C) Rev. Educ. Perspec. & Viçosa, $M G$ & v.9 & n.1 & p.30-47 & jan./abr. 2017 & eISSN 2178-8359 \\
\hline
\end{tabular}


no exercício da atividade, no contato com a realidade, que é possível estabelecer estratégias e metodologias que viabilizam a efetivação com sucesso da atividade profissional.

Pela prática reflexiva, o professor consegue atingir uma ação autônoma e, dessa forma, tem claro as intencionalidades inerentes às suas ações. O professor reflexivo é um professor que detém o saber fazer, que domina as competências técnica e política de sua condição de ser e estar na profissão.

Segundo Nóvoa (1995), o processo de construção da identidade docente exige a superação de muitos obstáculos, entre os quais a submissão do professor ao controle político-estatal e sua função de reprodutor ideológico; a desvalorização do saber da experiência; a ausência do trabalho coletivo entre os professores.

Outro obstáculo a ser vencido, é a necessidade de construir um saber a partir da própria prática, isto é, de experiências pedagógicas concretas, um saber que, pelo exercício reflexivo, dialogue com as teorias das ciências humanas e sociais.

O processo identitário docente é uma construção permanente, permeada pelos diversos saberes com os quais o professor se relaciona no seu cotidiano. A atividade docente e, por conseguinte, a construção da identidade docente exige uma formação contínua e esse processo de formação não pode ser considerado e efetivado apenas por cursos formais, mas deve ser visto em toda a sua complexidade.

Segundo Moita (1992), a identidade pessoal é um sistema de múltiplas identidades. No interior dessa multiplicidade, situa-se a questão da identidade profissional.

É uma construção que tem uma dimensão espácio-temporal, atravessa a vida profissional desde a fase da opção pela profissão até à reforma, passando pelo tempo concreto da formação inicial e pelos diferentes espaços institucionais onde a profissão se desenrola. É construída entre saberes científicos e pedagógicos como sobre referências de ordem ética e deontológica. É uma construção que tem a marca das experiências feitas, das opções tomadas, das práticas desenvolvidas, das continuidades e descontinuidades, quer ao nível das representações quer ao nível do trabalho concreto (MOITA, 1992, p. 116).

No percurso de sua formação identitária, o professor relaciona-se com diferentes saberes, que vão constituindo-se nos processos parciais de formação, na confluência dos quais, segundo Dominicé (1985 apud MOITA, 1992, p. 115), "é possível encontrar uma lógica singular, um modo único de os gerir e utilizar".

Em linha similiar, Penin (1995, p. 14) afirma que "antes de construir o conhecimento sobre o ensino, a professora assimila concepções já existentes, sistematizadas ou formuladas sob diferentes graus de sistematização pelo saber cotidiano (as chamadas representações sociais)

\begin{tabular}{l|c|c|c|c|c|c} 
() Rev. Educ. Perspec. & Viçosa, $M G$ & v.9 & n.1 & p.30-47 & jan./abr. 2017 & eISSN 2178-8359 \\
\hline
\end{tabular}


e vive o ensino".

Nessa perspectiva, no processo de construção de sua identidade, o docente relaciona-se com diferentes saberes, os quais, por sua vez, se relacionam com as representações dos professores sobre sua identificação e, portanto, tais saberes influenciam e são, ao mesmo tempo, influenciados pelos professores.

Penin (1993), afirmando a importância do estudo da prática pedagógica e da vivência que envolve essa prática no âmbito do cotidiano escolar, ancorada em Marx e Nietzsche, defende o resgate da valorização da vivência na Pedagogia. Segundo a autora, culturalmente tem pesado sobre a nossa civilização uma supervalorização do conhecimento sistematizado, ou seja, do discurso científico que, "apoiado na formulação positivista relativa à construção do conhecimento, instalou-se na modernidade, persistindo, ainda hoje, como saber-referência” (PENIN, 1993, p. 7).

Diante da constatação de que os estudos relativos à educação, à escola e ao ensino tiveram como referência marcante os parâmetros da cientificidade, portanto são tidos como conhecimentos válidos, mas não deram conta e nem esgotaram os fenômenos educacionais, Penin (1993) reforça a importância e a validade de tais estudos voltarem-se para a prática pedagógica, para a vivência docente. Antes do conceito de ensino ser formulado, já existiam as práticas pedagógicas, das quais deriva tal conceito.

Se o conhecimento sistematizado, que é impregnado não apenas por conceitos teóricos, como também por ideologias, influencia as representações dos professores sobre o ensino, também as vivências docentes vão interferir nessas representações e é "a partir da articulação que estabelece entre o concebido [conhecimento sistematizado] e o vivido [vivência] que o professor representa o ensino. Essa ou essas representações, por sua vez, influenciam seja seu discurso, seja sua prática de ensino" (PENIN, 1993, p. 8).

Depreendemos daí a importância de nos voltarmos para a cotidianeidade das práticas pedagógicas, incorporando o espaço da vivência docente, saber da experiência, que por sua vez, modela, adequa e transforma o saber sistematizado, tornando-o acessível ao aluno. As experiências e os saberes daí gerados não decorrem só da prática pedagógica, do exercício da função, mas precedem tal prática, iniciando-se com a nossa capacidade de nos perceber no mundo e se processa ao longo do tempo nos diversos espaços socioeducativos.

Retomando o conceito de identidade profissional dos educadores e professores, defendido por Moita (1992), que a considera uma construção, com dimensão espaço-temporal, que se estende desde a fase da opção pela profissão até aos diferentes espaços institucionais onde se efetiva, podemos concluir que a função docente é compósita, ou seja, constituída por 
diferentes saberes, com os quais os professores se relacionam ao longo do processo do constituir-se como professor.

Nessa direção, encontramos a afirmação de Feiman-Memser e Buchmann (1987), citados por Zeichner (1992, p. 130), de que "o processo de aprender a ensinar começa muito antes dos alunos freqüentarem os cursos de formação de professores".

O processo de formação da identidade docente se expressa na maneira de dar aulas, na forma como nos relacionamos e nos vinculamos com nossos alunos, com nossos pares professores, com os conteúdos, com os saberes, antecede o processo formal de nossa qualificação, que se materializa nos cursos de licenciatura.

Se a atuação de antigos professores influencia na opção pela profissão docente e pela área a ser exercida, também influenciará no exercício da função, na práxis docente. As lembranças de antigos mestres acabam por compor, juntamente com outros tantos fatores, o reservatório de saberes necessários e mobilizados, consciente ou inconscientemente, no ato de ser/estar na profissão docente.

Gauthier (1998), ao discutir a questão da profissionalização docente, defende a necessidade de se promover reflexões acerca dos conhecimentos necessários à função, asseverando que tal definição permite contornar

\footnotetext{
dois obstáculos fundamentais que sempre se interpuseram à pedagogia: primeiro, $\mathrm{o}$ da própria atividade docente, por ser uma atividade que se exerce sem revelar os saberes que lhe são inerentes; segundo, o das ciências da educação, por produzirem saberes que não levam em conta as condições concretas de exercício do magistério (GAUTHIER, 1998, p. 19).
}

Segundo o autor, esses obstáculos impediram a emergência de saberes profissionais, contribuindo, assim, para a preconcepção de ideias que prejudicam a profissionalização do ensino. Dentre tais preconcepções, destacamos as ideias de que, para ensinar, basta conhecer o conteúdo a ser ensinado, desconsiderando, nesse caso, saberes fundamentais à transmissão do conteúdo a ser trabalhado, tais como questões relacionadas ao planejamento de atividades, de avaliação, de relações interpessoais, de disciplina, entre tantas outras.

Dentre outras ideias preconcebidas, que contribuem para a instauração de um 'ofício sem saberes', Gauthier (1998) destaca as seguintes: que para ensinar: a) basta ter talento; b) basta ter bom senso; c) basta seguir a intuição; d) basta ter experiência; e, e) basta ter cultura. Segundo o autor, todas as ideias acima elencadas constituem saberes necessários ao ofício da docência, porém não são suficientes quando tomadas de maneira isolada umas das outras.

A consideração de uma ou outra das ideias acima, como suficientes para o exercício da docência contribui para o processo de "desprofissionalização" do ensino, na medida em que

\begin{tabular}{l|c|c|c|c|c|c} 
(C) Rev. Educ. Perspec. & Viçosa, $M G$ & v.9 & n.1 & p.30-47 & jan./abr. 2017 & eISSN 2178-8359 \\
\hline
\end{tabular}


impede o "desabrochar de um saber desse ofício sobre si mesmo" (GAUTHIER, 1998, p. 25). Por outro lado, tal consideração favorece o seu contrário, qual seja, o de propor "saberes sem ofício", reduzindo a complexidade do ensino ao desconsiderar "o professor real, cuja atuação se dá numa verdadeira sala de aula", substituindo esse "professor real" e essa "verdadeira sala de aula", por "uma espécie de professor formal, fictício, em que todas as variáveis são controladas” (GAUTHIER, 1998, p. 26). Nesse caso, o ensino fica mutilado, uma vez que desconsidera seus principais sujeitos, quais sejam, o professor, o grupo de alunos, a sala de aula, que se insere em uma sociedade maior, que, por sua vez, direta ou indiretamente estabelece os valores que sustentam e apoiam o ato de instruir e educar.

A não consideração do professor e de suas condições reais de atuação, traz consigo a não reflexão sobre a pluralidade de saberes que são mobilizados no exercício da função e que, em decorrência dessa não reflexão, são, na maioria das vezes, confinados à privacidade de experiências docentes isoladas que, embora possam ter grande validade e muitas contribuições para o processo de melhoria da qualidade do ensino, não são socializadas e, portanto, perdem-se no anonimato de cada docente.

A definição de Moita (1992), no tocante ao conceito de identidade profissional dos educadores, tomando-a como processual e compósita, ou seja, constituída de diferentes saberes, aponta, também, para a necessidade de reflexão sobre esses saberes.

Nessa perspectiva, o pensamento reflexivo sobre a prática docente possibilita desvelar os saberes que são mobilizados pelos professores nas mais diferentes situações de ensino, possibilitando, por sua vez, a definição dos saberes necessários ao ensino, logo, à sua profissionalização.

Na busca por dar visibilidade à complexidade do saber constituído no (e para o) exercício da atividade docente, foram sendo gestadas e sistematizadas, no bojo das discussões sobre a formação e profissionalização do professor, as reflexões acerca do "saber docente" (TARDIF; LESSARD; LAHAYE, 1991; PIMENTA, 1999; TARDIF, 2000). E os estudos e reflexões sobre os saberes docentes ganharam impulso quando buscaram identificar os diferentes saberes implícitos na prática docente.

Na realidade brasileira, foi a partir da década de 1990 que se buscaram novos enfoques para compreender a prática pedagógica e os saberes pedagógicos e epistemológicos relativos ao conteúdo escolar a ser ensinado. Nesta década teve início a proposição e desenvolvimento de pesquisas que, considerando a complexidade da prática educativa e dos saberes docentes, tomaram como centro de suas análises a formação do professor para além da academia, englobando o desenvolvimento pessoal, profissional e organizacional da profissão docente.

\begin{tabular}{l|c|c|c|c|c|c} 
() Rev. Educ. Perspec. & Viçosa, $M G$ & v.9 & n.1 & p.30-47 & jan./abr. 2017 & eISSN 2178-8359 \\
\hline
\end{tabular}


Gauthier (1998), concebe o ensino como a mobilização "de vários saberes que formam uma espécie de reservatório no qual o professor se abastece para responder a exigências específicas de sua situação concreta de ensino” (1998, p. 28). O autor identifica como necessários à profissionalização do ensino, os seguintes saberes: os disciplinares, os curriculares, os da ciência da educação, os da tradição pedagógica, os experienciais e os da ação pedagógica.

A análise e a reflexão sobre cada um desses saberes, por questões didáticas, ocorrerá aqui de forma compartimentada. No entanto, mister se faz considerar que é a mescla deles de forma integrada, interconectada e totalizante, que caracteriza, verdadeiramente, o repertório dos saberes docentes.

\section{A PLURALIDADE DOS SABERES DOCENTES}

\section{Os Saberes da Tradição Pedagógica}

Esses saberes são heranças de antigos mestres, uma vez que a tradição pedagógica remonta ao século XVII, quando é estruturada uma nova maneira de dar aulas, que até então era feita no singular, isto é, os mestres ensinavam individualmente, recebendo seus discípulos em seus respectivos escritórios. A partir de então, passa-se a praticar o ensino simultâneo, em uma sala mais ampla, dirigindo-se a todos os alunos ao mesmo tempo. Portanto, de singular, o ensino passou a uma prática coletiva.

Ao tornar-se coletivo, o ensino incorpora uma pedagogia baseada na ordem, que era aquela estabelecida pelas instituições religiosas. Já no século XVII, após a fase da hegemonia da Igreja, identifica-se a interferência do Estado na definição da ação dos professores e, portanto, nos saberes da tradição pedagógica.

O saber dar aulas da tradição pedagógica chegou até os dias atuais, não somente povoando as nossas recordações de infância, mas também embasando nossas representações de ser/estar docente, de escola, e, em consequência disso, interferindo e definindo uma boa parte do cotidiano das escolas.

Segundo Tardif (2000), boa parte dos saberes profissionais dos professores são adquiridos através do tempo e provém de sua própria história de vida, constituindo-se em uma bagagem de conhecimentos anteriores, de crenças, de representações e de certezas sobre a prática docente, que começa a se formar antes mesmo de começarem a trabalhar e, "quando começam a trabalhar como professores, são principalmente essas crenças que eles reativam para solucionar seus problemas profissionais” (TARDIF, 2000, p. 13-14).

\begin{tabular}{l|c|c|c|c|c|c} 
(C) Rev. Educ. Perspec. & Viçosa, $M G$ & v.9 & n.1 & p.30-47 & jan./abr. 2017 & eISSN 2178-8359 \\
\hline
\end{tabular}


É compreensível, assim, vez ou outra, pegarmos, a nós, professores que hoje somos, repetindo atos, gestos e atitudes ou, se refletirmos um pouco mais sobre tais considerações, buscando evitar determinadas práticas que condenamos em nossos mestres.

Assim, evidenciamos a importância de tais saberes, bem como a necessidade de reflexão sobre eles, de maneira a romper com os obstáculos e barreiras impostos pela tradição pedagógica, gestada em plena hegemonia da racionalidade técnica.

A reflexão sobre esses saberes implica, necessariamente, refletir sobre as representações que os professores têm/fazem da escola, do ensino e da profissão. As representações são, por sua vez, construções históricas, que recebem heranças/influências de concepções anteriores.

\section{Os Saberes Disciplinares}

Toda disciplina científica tem definido um objeto e um método de pesquisa e de estudo. A aplicação dos métodos, na busca da explicitação e contribuições dos objetos das disciplinas para o social, gera conhecimentos e informações das disciplinas que, apreendidas, constituem os saberes disciplinares.

Segundo Tardif, Lessard e Lahaye (1991), os saberes disciplinares são definidos por cientistas a partir dos saberes produzidos pelas ciências da educação e dos saberes pedagógicos, além dos saberes sociais, integrando-se à prática docente por meio da formação, tanto inicial quanto continuada, dos professores.

Também é importante não perder de vista a dinamicidade desses saberes, que não podem ser vistos como saberes prontos e acabados, já que tal visão acabaria por reduzir o docente a um simples 'reprodutor de conhecimentos'. Os saberes docentes não são saberes estáticos, definitivos, ao contrário, cada um deles é, conforme Barth (1993), citado por Fiorentini et al. (1999, p. 3), "provisório, pessoal, que evolui com o tempo e a experiência. Mas é também cultural, modificando-se a partir da troca de experiências e da reflexão coletiva”.

Esses saberes correspondem aos diversos campos do conhecimento, aos saberes de que dispõe nossa sociedade, tal qual encontram-se hoje integrados - sob a forma de disciplinas - à universidade, no quadro de faculdades e de programas distintos (TARDIF; LESSARD; LAHAYE, 1991, p. 220).

Nesse sentido, os saberes disciplinares constituem o 'corpus' de conhecimentos de uma determinada disciplina. Logo, deter os saberes disciplinares significa conhecer o conteúdo a ser transmitido, pois, para professar, para ensinar é preciso antes aprender, conhecer. Não se ensina aquilo que não se sabe.

\begin{tabular}{l|c|c|c|c|c|c} 
() Rev. Educ. Perspec. & Viçosa, $M G$ & v.9 & n.1 & p.30-47 & jan./abr. 2017 & eISSN 2178-8359 \\
\hline
\end{tabular}


Gauthier (1998) nos adverte para o fato de que, para ensinar, é necessário conhecer os saberes disciplinares. Entretanto, isto por si só, não basta, uma vez que, para o ensino ser significativo, é necessária a produção, na escola, de um saber a respeito dos conteúdos a serem ensinados, o que leva a uma transposição didática do saber científico ao saber escolar. Isso confirma que "o professor não produz o saber disciplinar, mas, para ensinar, extrai o saber produzido por esses pesquisadores” (GAUTHIER, 1998, p. 29).

Nesse sentido, concordamos com Gauthier (1998) e acrescentamos as reflexões de Bittencourt (2008), de que a escola é um espaço contraditório, um lugar de produção de conhecimento, e não apenas mera instância criada pelo Estado para transmitir e reproduzir ideologias. Dessa forma, compõem o saber escolar: 'o saber a ser ensinado', difundido pelas disciplinas escolares distribuídas pelos programas e currículos escolares; o saber a ser ensinado transforma-se em 'saber ensinado' na sala de aula, onde o professor é elemento fundamental na interpretação que fornece a esse conhecimento proposto a partir dos métodos que utiliza em sua transmissão e os meios de comunicação disponíveis; e o 'saber aprendido', ou seja, o conhecimento incorporado e utilizado pelos alunos de acordo com a vivência de cada um deles, das condições sociais e das relações estabelecidas no espaço escolar.

Conforme Grossman (1990), citado por Gauthier (1998, p. 30), "as pesquisas vêm mostrando, cada vez mais, que o tipo de conhecimento que o professor possui a respeito da matéria influi no seu ensino e na aprendizagem dos alunos". Isso implica que não basta conhecer o conteúdo a ser ensinado, é necessário buscar a adequação e adaptação de tais conteúdos à realidade do aluno, o que só é possível por meio da mobilização de outros saberes, como os da experiência, por exemplo.

O exercício de tornar ensinável os saberes disciplinares, tidos como científicos, torná-los acessíveis aos alunos, implica, necessariamente, conhecer a realidade desses alunos, seu mundo e suas condições de vida. Implica, também, conhecer a realidade escolar, o 'estar' sendo professor, o convívio no espaço da sala de aula. Isso envolve e requer do professor uma constante retroalimentação, tanto na busca da atualização dos saberes disciplinares, quanto na mobilização de outros saberes, necessários ao exercício de seu ofício. Dentre tais saberes destacamos os saberes curriculares.

\section{Os Saberes Curriculares}

Os saberes curriculares "correspondem aos discursos, objetivos, conteúdos e métodos, a partir dos quais a instituição escolar categoriza e apresenta os saberes sociais que ela definiu e selecionou como modelo da cultura erudita" (TARDIF; LESSARD; LAHAYE, 1991, p. 220). Nesse sentido, conhecer esses saberes é fundamental para a integração do conteúdo, dos saberes disciplinares, aos saberes sociais, tidos como modelos da cultura erudita.

\begin{tabular}{l|c|c|c|c|c|c} 
() Rev. Educ. Perspec. & Viçosa, $M G$ & v.9 & n.1 & p.30-47 & jan./abr. 2017 & eISSN 2178-8359 \\
\hline
\end{tabular}


A concepção desses saberes materializa-se, em termos de Brasil, numa direção do macro (País) ao micro (escola), nos Parâmetros Curriculares Nacionais (PCNs) e Base Nacional Curricular Comum (BNCC); nas Propostas Curriculares (PC) dos Estados e Municípios e nos Projetos Político Pedagógicos (PPP) das escolas e aos Planos de Ensino dos professores.

Conforme Gauthier (1998), os saberes curriculares são frutos da transformação de saberes produzidos pelas ciências, que são selecionados e organizados sob a forma de Currículos e

esses programas não são produzidos pelos professores, mas por outros agentes, na
maioria das vezes funcionários do Estado ou especialistas das diversas disciplinas.
No Brasil, eles também são transformados pelas diversas editoras em manuais e
cadernos de exercícios que, uma vez aprovados pelo Estado, são utilizados pelos
professores (GAUTHIER, 1998, p. 30-31).

Uma vez que os saberes curriculares constituem o 'corpus' definidos como modelo da cultura erudita, é necessário o conhecimento dos mesmos, o que possibilita ao professor selecionar, dentre os saberes disciplinares, a relação dos conteúdos, objetivos e fins da educação.

Quando o docente não se interessa pelo conhecimento dos saberes curriculares e como no Brasil eles são transformados em livros didáticos, corre-se o risco de que o livro didático assuma a forma do currículo. Isto tem como consequência o uso generalizado desse recurso de ensino como principal instrumento de trabalho e, nesse caso, o livro, de material de apoio, assume o papel de sustentação de todo o trabalho docente.

Se o professor nem sempre é o agente produtor dos saberes curriculares, pode, entretanto, selecionar e adaptar esses saberes à realidade na qual atua.

\section{Os Saberes das Ciências da Educação}

O conjunto de saberes transmitidos pelas instituições de formação de professores embora nem sempre ligados aos conteúdos específicos propriamente ditos, constituem os saberes das ciências da Educação e visam informar aos professores a respeito das várias facetas de seu ofício ou da Educação de um modo geral.

Via de regra, no Brasil, em termos de cursos de formação inicial de professores, esses conhecimentos são transmitidos pelas chamadas disciplinas 'pedagógicas', como por exemplo, a Didática, a Estrutura e Funcionamento do Ensino, a Psicologia da Educação, as Metodologias de Ensino, o Estágio Curricular Supervisionado, dentre outras.

Em geral, são os saberes das ciências da educação que constituem o arcabouço científico que distingue o professor dos demais profissionais da área específica do conhecimento,

\begin{tabular}{l|c|c|c|c|c|c} 
(C) Rev. Educ. Perspec. & Viçosa, $M G$ & v.9 & n.1 & p.30-47 & jan./abr. 2017 & eISSN 2178-8359 \\
\hline
\end{tabular}


diferenciando, por exemplo, o geógrafo do professor de Geografia, o historiador do professor de História e assim por diante.

\begin{abstract}
o professor possui noções relativas ao sistema escolar, sabe o que é um conselho escolar, um sindicato, uma carga horária. Talvez tenha também uma idéia da evolução de sua profissão, e domina determinadas noções sobre o desenvolvimento da criança, as classes sociais, os estereótipos, a violência entre os jovens, a diversidade cultural, etc (GAUTHIER, 1998, p. 31).
\end{abstract}

Nessa perspectiva, comungamos, mais uma vez, com Nóvoa (1992) o reconhecimento da importância de se considerar a 'internalidade' do processo educativo, voltando nossos olhares para a prática pedagógica do docente, que é o 'locus' privilegiado na produção de saberes.

Assim, se é na teoria, conforme ressaltam Tardif, Lessard e Lahaye (1991, p. 219), "sobretudo por ocasião de sua formação que o(a)s professore(a)s entram em contato com as ciências da educação", será na prática, na experiência que esses saberes serão mobilizados, conforme as diversidades impostas pela dinamicidade social os requererem. E, ainda, ao mobilizar tais saberes, os docentes acabam por incorporá-los à sua práxis, adaptando-os e produzindo novos saberes.

\title{
Os Saberes da Experiência
}

Como abordamos anteriormente, o processo de ser/estar na profissão docente é um processo histórico que antecede a opção pelo curso de formação inicial. Assim, também no que se refere aos saberes da experiência, podemos afirmar que os mesmos são construídos já a partir de nossa condição de estudantes, quando obtemos, pela observação, experiências para dizer quais foram os nossos melhores professores, quais dominavam o conteúdo e as 'formas' de transmissão dos mesmos, etc.

Em outro nível, no da prática, os saberes da experiência "são também aqueles que os professores produzem no seu cotidiano docente, num processo permanente de reflexão sobre a sua prática, mediatizada pela de outrem - seus colegas de trabalho, os textos produzidos por outros educadores” (PIMENTA, 1999, p. 20).

Nessa direção, os professores são tomados como os produtores de seus próprios saberes, quando, no exercício de sua função docente, desenvolvem truques, esquemas e estratagemas que lhes possibilitem superar as mais diversas situações, que, embora corriqueiras, são dinâmicas. Essas técnicas, truques e estratagemas desenvolvidos pelo docente na 'solidão' de si com suas 'repletas' salas de aulas são saberes que the são particulares e, se não socializados, permanecem em segredo.

\begin{tabular}{l|c|c|c|c|c|c} 
() Rev. Educ. Perspec. & Viçosa, $M G$ & v.9 & n.1 & p.30-47 & jan./abr. 2017 & eISSN 2178-8359 \\
\hline
\end{tabular}


Gauthier (1998) nos adverte que, embora o professor viva as mais diversas experiências, das quais retira grande proveito, elas infelizmente, permanecem confinadas ao segredo da sala de aula. $\mathrm{O}$ confinamento de experiências positivas às fronteiras da sala de aula impede uma reflexão mais crítica sobre elas e, assim, deixamos de fazer o elo de ligação e mútua retroalimentação da prática/teoria/prática.

Práticas docentes positivas, quando experienciadas, debatidas e socializadas contribuem para a superação de inúmeras dificuldades de docentes, principalmente daqueles em início de carreira.

A reflexão e publicação dos saberes experienciais nos levam aos saberes da ação pedagógica.

\section{Os Saberes da Ação Pedagógica}

A investigação e a reflexão sobre a prática docente revelam que o professor, no exercício de sua função, diante das mais variadas situações e realidades sócio-histórica-culturais, mobiliza diferentes saberes, conforme a situação o exigir. Na mobilização desses saberes o professor acaba por elaborar diversos truques e estratagemas que funcionam e que, no entanto, nem sempre são socializados, privando, assim, outros colegas de tais recursos.

Quando a prática docente é observada, testada e validada, aqueles 'truques' e estratégias são publicados/divulgados, transformando-se, então, nos chamados saberes da ação pedagógica e, nesse caso, contribuem para o abastecimento do repertório dos saberes de outros docentes.

A manutenção dos saberes experienciais no anonimato do trabalho daqueles que os produzem caracteriza uma espécie de 'egoísmo', pois priva seus pares do conhecimento de experiências positivas. Conforme assevera Gauthier (1998, p. 34):

De fato, na ausência de um saber da ação pedagógica válido, o professor, para fundamentar seus gestos, continuará recorrendo à experiência, à tradição, ao bom senso, em suma, continuará usando saberes que não somente podem comportar limitações importantes, mas também não o distinguem em nada, ou em quase nada, do cidadão comum.

Os saberes da ação pedagógica nascem, portanto, da observação empírica dos saberes experienciais que, uma vez testados e validados, rompem com a privacidade e a respectiva manutenção dos mesmos como atividades produtivas, desenvolvidas em situações concretas de sala de aula e que, no entanto, na maioria das vezes, são confinadas ao segredo de alguns professores.

O exercício da prática reflexiva, que desperta no professor o triplo movimento definido por Shön (2000), como reflexão na ação, reflexão sobre a ação e reflexão sobre a reflexão na

\begin{tabular}{l|c|c|c|c|c|c} 
(C) Rev. Educ. Perspec. & Viçosa, $M G$ & v.9 & n.1 & p.30-47 & jan./abr. 2017 & eISSN 2178-8359 \\
\hline
\end{tabular}


ação, é que possibilita a materialização dos saberes da ação pedagógica, colocando o professor como produtor desses conhecimentos, ou seja, deixar de ser apenas o objeto de observação e transformar-se no sujeito de tais saberes.

A prática reflexiva, ou melhor, a reflexão na ação propicia uma visão crítica frente ao conhecimento e discernimento sobre a validade, aplicabilidade e praticidade de determinados conteúdos e metodologias. A reflexão na ação ocorre simultaneamente ao agir, sendo que tal prática possibilita ao professor consciência e clareza em exemplos práticos dos conteúdos trabalhados. Essa reflexão na ação impulsiona a um segundo movimento que é o da reflexão sobre a ação.

A reflexão sobre a ação é o exercício que o professor se habitua a executar quando, ao planejar suas ações futuras, suas aulas e suas atividades, passa a refletir sobre sua prática, a questionar e a rever, quando necessário, posicionamentos, atitudes e práticas cotidianas.

Completando o triplo movimento sugerido por Shön (2000), para a formação do professor reflexivo, tem-se o movimento da reflexão sobre a reflexão na ação.

O refletir sobre a reflexão na ação é que torna o professor não só produtor de saberes, como também socializador desses saberes, uma vez que a reflexão sobre a reflexão na ação revela ao professor os limites e possibilidades de sua prática, levando-o não apenas a mobilizar saberes, como também a revê-los, reelaborando-os, quando necessário, fazendo, nesse caso, o movimento de retroalimentação que caminha da prática para a teoria e desta retornando à prática.

É importante considerar também que os saberes da ação pedagógica podem romper com a dicotomia teoria/prática ainda recorrente na prática escolar. Esses saberes podem e devem contribuir como um novo repertório de conhecimentos nos cursos de formação inicial e continuada, além de contribuir para o avanço do processo de profissionalização.

Por serem frutos da ação concreta dos professores, ação essa que incorpora, tantos outros saberes que fazem parte do imaginário e das representações docentes sobre o aluno, o ensino, a escola e a educação, os saberes da ação pedagógica são constitutivos da identidade profissional do professor.

Temos, então, que a identidade docente é compósita e processual, ou seja, constituída por diversos saberes que são permanentemente mobilizados, incorporados e/ou modificados e transformados em novos saberes, que funcionam como a mola propulsora do ser/estar na profissão docente.

\begin{tabular}{l|c|c|c|c|c|c} 
() Rev. Educ. Perspec. & Viçosa, $M G$ & v.9 & n.1 & p.30-47 & jan./abr. 2017 & eISSN 2178-8359 \\
\hline
\end{tabular}




\section{CONCLUSÃO}

No decorrer de nossa escrita ressaltamos a relação entre os professores e os saberes, bem como, a relevância da socialização desses saberes para a construção da identidade docente tendo como locus o Estágio Curricular Supervisionado.

Isso implica em superar concepções oriundas do paradigma da racionalidade técnica, que ao considerar o professor como mero técnico, transmissor de saberes, simplifica processos, desconsidera subjetividades e potencialidades dos professores, desqualificando-o como profissional. Significa, também, questionar conclusões, que tendem a culpabilizar os docentes pelo fracasso da escola e dos alunos.

A noção de saber trabalhada, foi num sentido amplo, que engloba os conhecimentos, as competências, as habilidades e as atitudes, muitas vezes chamadas de 'saber', 'saber fazer' e 'saber ser'. Em síntese, uma epistemologia da prática profissional, utilizada pelos profissionais em seu espaço de trabalho cotidiano para desempenhar todas as suas tarefas (TARDIF, 2012).

A reflexão sobre esses saberes é o caminho que aponta rumo à profissionalização do ensino e, com isso, valorização e consequente melhoria na qualidade do ensino, baseada na experiência da prática e críticas realizadas com embasamento teórico e sensibilidades no habitus de ser professor.

\section{REFERÊNCIAS}

BARTH, Britt-Mari. O saber em construção - para uma pedagogia da compreensão. Coleção Horizontes Pedagógicos, Instituto Piaget, Lisboa, Portugal: 1993. 256p.

BITTENCOURT, Circe. Livro didático e saber escolar (1810-1910). Belo Horizonte: Autêntica 2008. 240 p.

DOMINICÉ, Pierre. Ce que la vie leu r a appris. In: FINGER, Matthias, JOSSO, Christine (ed.). Pratiques du récit de vie et théories de la formation. Geneve: FPSE/Université de Geneve, cahier 44, p. 99-121, 1985.

FEIMAN-NEMSER, Sharon; BUCHMANN, Margaret. When is student teaching teacher education? Teaching and Teacher Education, v. 3, p. 255-273, 1987. 
FIORENTINI, Dario; NACARATO, Adair Mendes; PINTO, Renata Anastácio. Saberes da experiência docente em Matemática e Educação continuada. Campinas-SP: UNICAMP, 1999. (Mimeo).

GAUTHIER, Clermont. Por uma teoria da Pedagogia: pesquisas contemporâneas sobre o saber docente. Ijuí-RS: Unijuí, 1998. 480p.

GROSSMAN, Pamela Lynn. The Making of a Teacher. Teacher Knowledge and Teacher Education. New York: Columbia University, Teachers College Press, 1990.

MOITA, Maria da Conceição. Percursos de formação e de trans-formação. In: NÓVOA, António. Vidas de Professores. Porto, Portugal: Porto Editora, p. 111-140, 1992.

NÓVOA, António (Coord.). Os professores e sua formação. 2 ed. Portugal. Porto: Dom Quixote, 1995.

NÓVOA, António. Vidas de professores. Portugal. Porto: Porto Editora, 1992. 216p.

PENIN, Sonia Teresinha de Sousa. A professora e a construção do conhecimento sobre o ensino. Cadernos de Pesquisa, n. 92, p. 5-15, 1995.

PENIN, Sonia Teresinha de Sousa. Cotidiano escolar e ensino: conhecimento e vivência. Revista da Ande, n. 19, p. 5-10, 1993.

PIMENTA, Selma Garrido (Org.). Saberes Pedagógicos e atividade docente. São Paulo: Cortez, 1999. 246p.

PIMENTA, Selma Garrido; LIMA, Maria Socorro Lucena. Estágio e Docência. 5. ed. São Paulo: Cortez, 2010. 256p.

SCHÖN, Donald A. Educando o profissional reflexivo: um novo design para o ensino e aprendizagem. Porto Alegre: Artes Médicas, 2000. 256p.

TARDIF, Maurice. Saberes profissionais dos professores e conhecimentos universitários. Elementos para uma epistemologia da prática profissional dos professores e suas consequências em relação à formação para o magistério. Revista Brasileira de Educação, n. 13 , p. 5-24, 2000.

TARDIF, Maurice. Saberes docentes e formação profissional. 13. ed. Rio de Janeiro: Vozes, 2012. 328p.

TARDIF, Maurice; LESSARD, Claude; LAHAYE, Louise. Os professores face ao saber. Esboço de uma problemática do saber docente. Teoria \& Educação. n. 4, p. 215-233, 1991. 
ZEICHNER, Ken. Novos caminhos para o practicum: uma perspectiva para os anos 90. In: NÓVOA, António. Os Professores e a sua formação. Lisboa: Instituto de Inovação Educacional, p. 115-138, 1992.

\section{SOBRE OS AUTORES}

\footnotetext{
${ }^{i}$ Vilmar José Borges: Doutor em Educação Escolar pela Universidade Estadual Paulista "Professor Júlio de Mesquita Filho". Professor Adjunto do Departamento de Educação, Política e Sociedade, do Centro de Educação da Universidade Federal do Espírito Santo. E-mail: vilmar.geo@ gmail.com ORCID: http://orcid.org/0000-0002-0846-0621

${ }^{i i}$ Regina Celi Frechiani Bitte: Doutora em Educação pela Universidade Federal do Espírito Santo. Professora Adjunto do Departamento de Educação, Política e Sociedade do Centro de Educação da Universidade Federal do Espírito Santo. E-mail: reginabitte@yahoo.com.br - ORCID:

http://orcid.org/0000-0001-6819-3900
} 